\title{
Study of Organizational Culture Assessment Model Based on Balanced Scorecard and Its Application
}

\author{
Yongbo Ding ${ }^{1}$,Xiangxi Ji ${ }^{2}$ \\ School of Business Administration, Jilin University of \\ Finance and Economics, Changchun, Jilin ,China \\ dybke@163.com
}

\author{
Chao $\mathrm{Ma}^{3}$ \\ School of Management, Jilin University, \\ Changchun, Jilin ,China \\ zhoubx@jlu.edu.cn
}

\begin{abstract}
Building corporate culture assessment model based on balanced scorecard provides a new approach to corporate culture assessment. 12 measures for the three perspectives of Customer, Internal Process and Learning and Innovation are selected in this thesis, which are customer orientation, social responsibility, staff satisfaction, participation, core values, information flow, team orientation, conformance, sense of mission, leadership, corporate learning and corporate innovation, and exemplified in their application to an energy company, thus enriching the content and extending the horizon of organizational culture assessment study, and providing a new approach to and way of thinking for it.
\end{abstract}

Keywords-organizational culture; balanced scorecard; organizational culture assessment

\section{INTRODUCTION}

Through the former related studies, it can be seen that scholars each have their own emphases in organizational culture assessment study. However, presently very few scholars evaluate organizational culture from strategic angle. Organizational culture construction based on strategy is a long-term and overall scheme for organizational culture. Balanced scorecard is elevated from performance management to strategic level, as a new organizational strategy management tool. Therefore, this thesis strives to construct an organizational culture assessment model based on balanced scorecard, and through application of the model, assesses the organizational culture of a company being researched, creating a new way to study, and making a healthful try for expanding the study of organizational culture assessment theory.

\section{MODEL CONSTRUCTION}

\section{A Basic Thinking}

As a new strategic management tool, the basic thinking behind Balanced Scorecard is to evaluate a company's strategic management performance from the four perspectives of finance, customer, internal process, and learning and innovation. Regarding this, the organizational culture assessment within the strategic view should also be done from the above-mentioned four perspectives to ensure the smooth implementation of organization strategy in the four aspects. Therefore borrowing the idea of balanced scorecard and considering the characteristics of organizational culture, this thesis chooses to conduct organizational culture assessment from the three perspectives of customer, internal process, and learning and innovation.

\section{B Choosing Measures}

Based on balanced scorecard, this thesis chooses 12 measures from the three perspectives of customer, internal process, and learning and innovation, and 91 specific targets to construct organizational culture assessment model. The details are shown in Table 1.

TABLE1 .KEY MEASURES FOR ORGANIZATIONAL CULTURE ASSESSMENT

\begin{tabular}{|l|l|}
\hline $\begin{array}{l}\text { Organizational } \\
\text { culture perspectives }\end{array}$ & $\begin{array}{l}\text { Organizational } \\
\text { culture assessment measures }\end{array}$ \\
\hline \multirow{4}{*}{ Customer } & Customer orientation $(\mathrm{CO})$ \\
\cline { 2 - 2 } & Social responsibility(SR) \\
\cline { 2 - 2 } & Staff Satisfaction(SS) \\
\hline \multirow{5}{*}{ Internal process } & Staff participation $(\mathrm{SP})$ \\
\cline { 2 - 2 } & \multicolumn{1}{|c|}{ Core values(CV) } \\
\cline { 2 - 2 } & Information flow(IF) \\
\cline { 2 - 2 } & Team orientation(TO) \\
\cline { 2 - 2 } & Conformance(CT) \\
\cline { 2 - 2 } & Sense of mission(MS) \\
\cline { 2 - 2 } & Leadership(LS) \\
\hline \multirow{4}{*}{$\begin{array}{l}\text { Learning and } \\
\text { innovation }\end{array}$} & Corporate innovation(CI) \\
\cline { 2 - 2 } & Corporate learning(CL) \\
\hline
\end{tabular}

12 dimensions of specific indicators as follows:

Customer orientation( $\mathrm{CO})$ :

(1) Customer suggestions and opinions are drivers for company reform.(2)Customer suggestions will affect our decisions.(3)Have an in-depth knowledge of customer needs.(4)Customer interests are considered first when we make decisions.(5)The development and improvement of new products are mainly based on information feedback from customers and the market.(6)There is an assessment system for customer service level.(7)The company has a speedy response to customer feedback or complaints.(8)Be able to get quick feedback about information of market change and get problem-solving measures.

Social responsibility(SR):

(1)The company is actively involved in social charity events.(2)The company encourages and organizes staff to volunteer in charitable activities.(3)The company complies with government requirements and legal regulations.(4)The company abides by social norms and moral rules.(5)The company actively involves in solving social problems.(6)Whether the company can go against social norms and moral rules. 


\section{Staff satisfaction(SS):}

(1)From today on, you hope to stay in the company for more than two years. (2)You like your present job very much.(3)The company is greatly concerned about its staff (Whether the company cares about you personal problems or difficulties.)(4)I am very satisfied with my colleagues.(5) I have a happy mood every day when at work. (6)Staff promotion is based on personal ability and performance.(7)I am very satisfied with my income level.(8)I think the company's assessment system is fair to me.(9)If another company provides better salary and benefits, I will leave this company.(10) I can get good benefits. (11)The company provides me with good development space and chances.(12)The working environment makes me feel comfortable and safe.

\section{Staff participation (SP):}

(1)In meetings everyone participates in discussions. (2)You think your effort will have a positive effect on the company's development.(3)Everybody will be involved in the company's plans in some degree. (4)I can decide on my own actions within certain boundaries.(5)Every employee has distinct work expectation and responsibilities.(6)The immediate superior will not interfere with my work directly after assigning work to me.(7)The company leaders take our opinions into consideration when making decisions.(8)My opinions will also be considered by the company. (9)I will be asked about how work will be improved.(10)The company encourages the staff to give suggestions or opinions on company development.

\section{Core values $(\mathrm{CV})$ :}

(1)There are moral standards to tell the right behaviors from the wrong.(2)Ignoring core values will put you in plight.(3)The company has persistent values to direct the company's business.(4)The company's leaders often stress on organizational values.(5)The company's values are deeply rooted in people's heart and receive wide recognition.

\section{Information flow(IF):}

(1)I can get sufficient information to complete my work with excellence.(2)I know the conditions of other departments.(3)When changes happen to the company, we will be informed of the reasons.(4) Information is widely shared, and everyone can get the information he wants.(5)The company has good information channel to ensure that the leaders know staff opinions.(6)I can know the company's big decisions through formal channels.(7) Communications and exchanges can be done between the departments, and information can be shared. (8)The company's leaders share with the staff members the latest news about the development of the industry and the company.

Team orientation(TO):

(1)Projects are finished by teams.(2)Team members are patient and serious when listening to other people's opinions.(3)My coworkers can actively take my opinions.(4)Among my colleagues, we trust and respect each other.(5)My colleagues are honest and friendly.(6)The team members have strong teamwork spirit.(7) Coworkers will provide help when I meet with difficulties in work.(8)
Even if the work product belongs to the collective, rewards are given according to individual performance.

Conformance(CT):

(1)Different departments in the company can coordinate projects easily.(2)Dealing with colleagues from other department is like dealing with people from other companies.(3)The recreational activities and sports held by the company can enhance colleague relations.(4)When disagreement appears, we try to reach a win-win position.(5)There is a strong cultural atmosphere.(6)On difficult problems, usually we can also reach agreement.

\section{Sense of mission(MS):}

(1)I know clearly our company's long-term goal, vision and strategy.(2)The company's vision is widely recognized in the company.(3)The vision stimulates and encourages the staff.(4)I can understand the entrepreneurship and guide or bind my behaviors accordingly.(5)A clear mission makes my job more meaningful.(6)The leaders will set ambitious but not unachievable goal.(7)I know clearly what to do for our long-term development and success.(8)The company thinks short-term benefit is more important than long-term success.

\section{Leadership(LS):}

(1)Leaders describe the task of a job clearly explicitly. (2)My direct superior can direct me and help me so that my job goes on efficiently.(3)Company leaders can listen to staff's opinions and suggestions seriously and patiently.(4)Company leaders can take opposite opinions or suggestions.(5)My superiors will point out my problems with a gentle attitude.(6)Top managers set examples for staff with their behaviors.

\section{Corporate innovation $(\mathrm{CI})$ :}

(1)Company leaders only care about the result of the staff's work.(2)The company encourages staff's innovation.(3)The company's operating methods are flexible and changeable.(4)You show your support for the company's constantly changing operating methods. (5)You are brave in introducing new ideas.(6)We can get sufficient information materials to innovate. (7)When in need, we can get efficient assistance from professionals.(8)At work I will actively search for and apply new technologies, new procedures or new methods.

\section{Corporate learning(CL):}

(1) The company provides us with fine learning atmosphere.(2)The company is concerned about providing learning and training opportunities for us.(3) After working and learning in the company, I am competitive among peers.(4)I think failure provides a chance for learning and growth.(5)I can improve my skills and capabilities in the company.(6)The company thinks the staff's capabilities an important source for the company's competitiveness. 


\section{MODEL APPLICATION}

\section{A Questionnaire Design and Data Collection}

The sample company for this study is ZJDD Gas Group. The questionnaire includes two parts, the first part being the basic condition of people being surveyed, including sex, age, educational background, working life and post. The second part is based on the organizational culture assessment model developed by this thesis, designing the questionnaire according to 12 measures to learn about the present condition of the company's organizational culture. We adopt 5-point Likert Scale for assessment, ranging from 1 to 5 (completely agree $=5$, basically agree $=4$, kind of agree $=3$, basically disagree $=2$, completely disagree $=1$ ) to show the degree how the staff support the stated opinions in 91 questions. Among them, 3 is taken as a dividing point, above which the staff show positive attitude toward the opinion, while below it the staff show negative attitude toward the opinion.

Before giving out questionnaires, we did survey testing, and modified the questions in the questionnaire which were difficult to answer. The survey lasted from September, 2010 to March, 2011. Altogether 250 questionnaires were given out and 245 were taken back. In the 245 questionnaires 42 were invalid data and were deleted. The valid questionnaires amount to 203. The distribution of questionnaires was done through random sampling to ensure the authenticity of data.

\section{B Data Analysis of Organizational Culture Assessment} Scales

Data are treated and analyzed through SPSS12.0, and descriptive statistical analysis and factorial analysis are done on organizational culture assessment indicators.

\section{1) Descriptive Statistical Analysis}

It can be seen from the valid questionnaires that $54.2 \%$ of the respondents have a middle or higher position, while first-line employees take up $45.8 \%$. This proves the authenticity of the questionnaires to a great extent. The oldest surveyed person is 52 years old, while the youngest 19. Staff under 25 years old make up $32.0 \%$, while staff ranging from 26 to $35,48.3 \%$, from 35 to $45,11.3 \%$, and over 45 years old, $8.4 \%$. Among the people being surveyed, males take up 59.6\%, while females, $40.4 \%$, and people with at least a college degree number 141 , accounting for $69.5 \%$.

\section{2) Factorial Analysis}

TABLE 2 KMO'S AND BARTLETT'S DETECTION

\begin{tabular}{|c|c|c|}
\hline $\begin{array}{r}\text { Kaiser-Meyer-Olkin } \\
\text { adeq }\end{array}$ & $\begin{array}{l}\text { measure of sampling } \\
\text { lacy }\end{array}$ & .899 \\
\hline \multirow{3}{*}{ Bartlett test of sphericity } & Approximate chi-square & 17514.842 \\
\hline & df & 2556 \\
\hline & Sig. & .000 \\
\hline
\end{tabular}

Before using SPSS12.0 statistical analysis software to do factorial analysis, we should first take a look at KMO result, as $\mathrm{KMO}$ result is an important measurement index for checking whether factorial analysis can be done on the data. The bigger the KMO result, the more the common factors, and the more appropriate it is to do factorial analysis. Kaiser(1974) thinks if
KMO is smaller than 0.5 , factorial analysis is not appropriate. As is shown in Table 2, the KMO result here is 0.899 , so it shows factorial analysis can be done on this assessment scale. Meanwhile, Bartlett test of sphericity shows the Sig to be 0.00 , meaning it is significant and factorial analysis can be done. Factor analysis results are as the followings:

Measure 1-CO:in customer orientation measure, two indicators $\mathrm{CO} 1=0.646$ and $\mathrm{CO} 2=0.587$ are deleted, and six are left,and eight are left,which are $\mathrm{CO} 3 、 \mathrm{CO} 4 、 \mathrm{CO} 5 、 \mathrm{CO}$ 、 CO7、CO8.

Measure 2-SR:in corporate social responsibility measure, the indicator SR6 $=0.45$ is deleted, and five are left,and eight are left,which are SR1、SR2 、SR3、SR4 、SR5.

Measure 3-SS: in company staff satisfaction measure, four indicators SS4 $=0.644, \mathrm{SS} 10=0.498, \mathrm{SS} 1=0.476, \mathrm{SS} 9=0.217$ are deleted, and eight are left,and eight are left,which are SS2 、SS3 、 SS5 、SS6、SS7、SS8 、SS11 SSS12 .

Measure 4-SP : in staff participation measure, two indicators SP2 $=0.651$ and SP $10=0.459$ are deleted, and eight are left,and eight are left,which are SP1、SP3、SP4、SP5、 SP6 、SP7、SP8、SP 9.

Measure 5-CV:in core values measure, the five indicators are all bigger than 0.7 , and therefore are all valid indicators and all kept, and eight are left,which are CV1、CV2、CV3、 CV4、CV5.

Measure 6-IF:in information flow measure, two indicators IF $1=0.643$ and IF2 $=0.177$ are deleted, and six left, and eight are left, which are IF3、IF4 、IF5 、IF6 、 IF7 、 IF8 .

Measure 7-TO:in team orientation measure, two indicators $\mathrm{TO} 2=0.611$ and $\mathrm{TO} 8=0.426$ are deleted, and six are left, and eight are left, which are TO1、TO3 、 TO4 、 TO5 、 TO6 、 TO7.

Measure 8-CT:in conformance measure, the indicator CT2 $=0.421$ is deleted, and five are left,and eight are left,which are CT1、CT3、CT4、CT5、CT6.

Measure 9-MS:in sense of mission measure, three indicators $\mathrm{MS} 1=0.682, \mathrm{MS} 6=0.592$ and $\mathrm{MS} 8=0.484$ are deleted, and five are left,and eight are left,which are MS2、 MS3、MS4、MS5、MS7.

Measure 10-LS:in leadership measure, the six indicators are all bigger than 0.7, so they are all valid, and all kept, and eight are left,which are LS1、LS2、LS3、LS4、LS5、LS6.

Measure 11-CI:in corporate innovation measure, three indicators $\mathrm{CI} 2=0.697, \mathrm{CI} 1=0.187$ and $\mathrm{CI} 8=0.153$ are deleted and five are left,and eight are left,which are CI3、CI4、CI5、 CI6、CI7.

Measure 12-CL:in corporate learning measure, indicator CL3 $=0.693$ is deleted, and five are left,and eight are left,which are CL1、CL2、CL4、CL5、CL6.

In summary, delete the 21 invalid indicators above-mentioned from the 91 specific assessment indicators in the 12 measures in Figure 1, then are left 70 structural questions in the 12 measures assessing organizational culture. 


\section{Reliability and Validity Analysis of the Organizational Culture Assessment Scale}

\section{1) Test of Its Reliability}

This thesis mainly tests the Cronbach's Alpha reliability, to test the internal consistency of the scale items and analyze whether there is any internal contradictions. Gullofdr points out that if Crnobahch's $\alpha$ is bigger than 0.7 , then the reliability is greater, and if it equals 0.7 , the reliability is at a critical point, relatively small but acceptable. If the $\alpha$ result is between 0.7 and 0.8 , it is considered quite good, and if bigger than 0.8 , it shows the scale has very good reliability. This thesis uses SPSS12.0 statistical software to analyze the reliability, and do $\alpha$ computations on the 12 measures this paper has been studying. See Table3.

TABLE 3 Reliability Analysis of ORganizational Culture ASSESSMENT SCALE

\begin{tabular}{|c|c|c|}
\hline Variable name & Item number & Cronbach' $\alpha$ \\
\hline Staff satisfaction & 12 & 0.898 \\
Team orientation & 8 & 0.871 \\
Information flow & 8 & 0.853 \\
Staff participation & 10 & 0.922 \\
Core values & 5 & 0.843 \\
Conformance & 6 & 0.753 \\
Sense of mission & 8 & 0.810 \\
leadership & 6 & 0.949 \\
Corporate innovation & 8 & 0.850 \\
Corporate learning & 6 & 0.850 \\
Customer orientation & 8 & 0.896 \\
Social responsibility & 6 & 0.810 \\
\hline
\end{tabular}

As is shown in Table 3 , among the 12 measures for the organizational culture assessment scale constructed by this thesis, only conformance's $\alpha$ result is $0.753(0.753>0.7$, and this measure also has quite a good reliability), while the other 11 measures's reliabilities are all greater than 0.8 , which proves the great reliability of the scale, or that the scale has a great stability.

\section{2) Validity Analysis}

It can be easily seen from the whole process of scale development and design to its application that both the measure design and the proposition of the indicators are founded on good theories and supported by a large amount of literature. The respondents all have stayed with the company for some time and have a good understanding of the company's organizational culture. The issues for the questions are mostly extracted from related foreign literature, and studied by both English language professionals and people from the company before they are fixed. They can be easily understood by staff and can reflect problems with accuracy, ensuring the face validity and content validity of the scale. The former reliability analysis and factorial analysis can also prove the validity of the scale. So we can conclude that the scale has a great validity.

\section{Organizational Culture Assessment Result}

Through statistical analysis, ZJDD Gas Group's total organizational culture score is 3.83 . The relatively high score indicates that the staff's overall appraisal of the company is positive. On the one hand, since its first foundation ZJDD Gas
Group has actively committed itself to organizational culture construction and infiltration, and has good organizational culture sediment. On the other hand, the staffs have been growing with the company's growth, so they have had a deep emotion for the company and some sense of belonging. Thirdly, ZJDD Gas Group is an energy company, and has got state and local support and help. Its sound development policies and fine prospect are attracting many employees to work hard for it. However, there are still some differences between the measures, though the total score of ZJDD Gas Group's organizational culture is very high. Among the measures staff participation measure scores the lowest (3.43), while social responsibility measure scores the highest (4.26), which basically conform to the feedback from interviews and focus groups, certifying the feasibility of the organizational culture assessment model developed in this thesis.

\section{CONCLUSION}

To sum up, this paper constructs an organizational culture assessment model based on balanced scorecard, and recognizes 70 structural questions to assess organizational culture, which can be categorized into 12 measures: customer orientation, social responsibility, staff satisfaction, participation, core values, information flow, team orientation, conformance, sense of mission, leadership, corporate learning and corporate innovation. Through its application to ZJDD Gas Group, it gives a total score of 3.83 for the company's organizational culture. Ranging from high to low according to the scores, the 12 measures come in the following order: learning, innovation, customer orientation, team orientation, staff satisfaction, sense of mission, leadership, conformance, core values, information flow and participation. The assessment result is basically consistent with ZJDD's organizational culture status.

\section{REFERENCES}

[1] Chen Chuanming, Zhang Min. Organizational Culture Rigidity: Analysis and Measurement[J].Management World,2005 (6) .

[2] William Ouchi. Theory Z: How American Management Can Meet the Japanese Challenge [M].Beijing : China Social Sciences Press, 1984.

[3] Wang Aiping. Let Organizational Culture Play the Role of Strategic Orientation [J].Shangxi Provincial Committee Party School Journal, 2009(7).

[4] Calori, R. and Sarnin, P. (1991), Corporate culture and economic performance: a French study", Organization Studies, Vol. 12 No. 1, pp. 49-74.

[5] Cameron, K. S. \& Quinn, R. E. (1998). Diagnosing and Changing Organizational Culture: Based on The Competing Values Framework. Addison2Wesley.

[6] De Long, D. W., \& Fahey, L. (2000). Diagnosing cultural barriers to knowledge management. Academy of Management Executive, 14(4), 113-127.

[7] Denison,D.R., Mishara, A. K.(1995). Toward a theory of organizational culture and effectiveness. Organization Science, Vol.6. No.2, March/ April pp.204-223

[8] Deshpande, R., Farley, J. U., \& Webster, J. (1993). Corporate culture, customer orientation and innovativeness in Japanese firms: A quadrad analysis. Journal of Marketing, 57(1), 22-27.

[9] Dombrowski, C., Kim, J. Y., Desouza, K. C., Braganza, A., Papagari, S. Baloh, P., et al. (2007). Elements of innovative cultures. Knowledge and Process Management, 14(3), 190-202.

[10] Hofsted, G., \& Neuijen, B. (1990). Measuring organizational cultures: a qualitative and quantitative study across twenty cases. Administrative Science Quarterly, 35(1990): 286-316. 